\title{
A Clinical Study on Dental Air Force Home Dental Cleaning System on Adult Chronic Periodontitis Patients and its Assessment to C-Reactive Protein Levels
}

\author{
Ameet Mani, Vinay Vadvadgi, Raju Anarthe, Rajiv Saini, Shubhangi Mani
}

\begin{abstract}
Aim: The study was outlined to determine and assess the C-reactive protein (CRP) level in chronic periodontitis patients and to assess the CRP values after using Dental Air Force home dental cleaning system.
\end{abstract}

Materials and methods: A total of 100 adult chronic periodontitis subjects were recruited voluntarily for this study. Clinical assessment of plaque index, gingival index, probing depth, clinical attachment level and C-reactive protein (CRP) levels were made prior to phase-1 therapy and at 7th and 15th day posttherapy. Effects of treatment were assessed by paired tests and analysis of variance by treatment group with baseline covariates. Comparative assessments were done among all the patients that were divided into four groups.

Results: The results of this study showed that there was 35\% decrease in CRP level in periodontitis patients that used Dental Air Force home dental cleaning system without undergoing phase 1 (complete scaling and root planing) therapy. There was $100 \%$ decrease in CRP in group D (phase 1 therapy followed by use of Dental Air Force home dental cleaning system) as compare to group C (phase 1 therapy followed by use of toothbrush) where there were $89.61 \%$ decrease in CRP level from baseline to 15th day of recordings.

Conclusion: There was strong correlation between periodontal diseases and CRP level and as there is progression and remission of periodontal disease; CRP values follow the same. Dental Air Force home dental cleaning system with the access to interdentally area helps in preventing the accumulation of dental plaque biofilm, thus able to maintain the CRP at lower levels as compare to traditional toothbrushing.

Keywords: Dental Air Force, CRP, Plaque, Biofilm.

How to cite this article: Mani A, Vadvadgi V, Anarthe R, Saini R, Mani S. A Clinical Study on Dental Air Force Home Dental Cleaning System on Adult Chronic Periodontitis Patients and its Assessment to C-Reactive Protein Levels. Int J Exper Dent Sci 2012;1(1):14-18.

Source of support: Nil

Conflict of interest: None declared

\section{INTRODUCTION}

Bacteria are the prime etiological agents in periodontal disease, and it is estimated that more than 500 different bacterial species are capable of colonizing the adult mouth ${ }^{1}$ and the lesions of the oral cavity have an immense impact on the quality of life of patient with complex advance diseases. ${ }^{2}$ Inflamed periodontal tissues produce significant amounts of proinflammatory cytokines, mainly interleukin 1-beta (IL-1 $\beta$ ), IL-6, prostaglandin E2, and tumor necrosis factor- alpha (TNF- $\alpha$ ), which may have systemic effects on the host. Periodontitis initiates systemic inflammation and can be monitored by inflammatory markers, such as C-reactive protein (CRP) or fibrinogen levels. ${ }^{3}$ Periodontitis has been proposed as having an etiological or modulating role in cardiovascular and cerebrovascular diseases, diabetes, respiratory disease and adverse pregnancy outcome. ${ }^{4}$ Observational nonexperimental studies have shown that subjects who have periodontal infections, such as gingivitis and periodontitis have higher levels of CRP than subjects without gingivitis and periodontitis respectively, supporting the hypothesis that these oral infections increase CRP levels. C-reactive protein was the first of many acute-phase reactants subsequently discovered, but today elevation of C-reactive protein is still considered the hallmark of the acute-phase response. The condition associated with the changes reflecting active inflammation and/or tissue necrosis is called the acute phase. During the acute phase, the increase in concentration and alteration of certain proteins of the blood was of great interest in this century, because they served as a diagnostic indication of the presence and extent of an inflammatory process or tissue necrosis. ${ }^{5}$ So, this study was outlined to determine and correlate the $\mathrm{C}$-reactive protein level in periodontitis patients and to evaluate the CRP values after using Dental Air Force home dental cleaning system.

\section{MATERIALS AND METHODS}

The present study was conducted in the Department of Periodontology, Rural Dental College, Loni in coordination with Department of Microbiology, Rural Medical College and Central Collection Laboratory (CCL) of Pravara Institute of Medical Sciences, Loni, Ahmednagar, Maharashtra, India. The research protocol was approved by the University Research and Ethical Committee.

\section{Study Population}

The subjects enrolled in this study were selected from the Outpatient Department of Periodontology, Rural Dental College and Hospital, Loni. After an informed consent, a total 100 chronic periodontitis patients between the ages of 
18 to 55 years voluntarily enrolled in the study and divided under four categories. Each group was comprised of 25 subjects each as illustrated in Table 1. Exclusion criteria included: (1) Presence of any systemic neurological disorder (e.g. epilepsy or schizophrenia), (2) presence of a disease with possible effects on the immune system (e.g. chronic infections or cancer), (3) patient who have received antibiotics or NSAIDs (like Ibuprofen) in past 9 to 11 weeks, (4) patients who have received periodontal treatment in past 6 months, (5) pregnant and lactating mother, (6) patient with artificial prosthesis, (7) patients who smokes or consumes tobacco in any form, (8) patients suffering with diabetes, arthritis any type of heart disease (MI, CHD, etc.), (9) female patients using intrauterine birth control devices or birth control pills, (10) obese individuals (30 and above range as per WHO BMI cutoff for weight categories for Asians), (11) participants not willing to participate in the study.

\section{Clinical Protocol}

Clinical parameter of periodontal disease evaluated in this study included gingival index (Loe \& Silness Index), plaque index (Turesky-Gilmore-Glickman modification of Quigley Hein Plaque Index), probing depth (PD) and clinical attachment level (CAL). Subjects under group A were advised to brush twice daily 5 minutes by modified bass method (technique demonstrated to each subject) and similar medium bristle toothbrush is provided to each of the subject during the study course. Subjects under group B were advised to use Dental Air Force home dental cleaning system twice daily for 5 minutes (technique demonstrated to each subject). Subjects under group C (after phase I therapy) were advised to brush twice daily 5 minutes by modified bass method (technique demonstrated to each subject) and similar medium bristle toothbrush is provided to each of the subject during the study course. Subjects under group D (after phase I therapy) were advised to use Dental Air Force home dental cleaning system twice daily for 5 minutes (technique demonstrated to each subject).

\section{Biochemical Analysis of CRP Estimation}

Baseline clinical and biochemical measurements were recorded of all the four groups. Full mouth scaling and root planing were carried out in patients belonging to groups $\mathrm{C}$ and $\mathrm{D}$. Recall visits were scheduled for all the subjects belonging to all the groups (A to D) on 7th and 15th day, both clinical and biochemical measurements were recorded. Venous blood samples were obtained from the antecubital vein by venipuncture using $2 \mathrm{ml}$ syringe from each subjects from all the four groups at baseline, 7th and 15th day. Scaling and root planing followed by use of toothbrush for group C and use of Dental Air Force home dental cleaning system for group D. Samples were then shifted to laboratory and processed with centrifuge machine at rate of 10,000 rpm to separate the serum and plasma from the blood. Serum was then analyzed for CRP using a commercially available kit.

\section{C-reactive Protein (CRP) Test}

RHELAX CRP slide test kit was used for the in vitro detection of CRP in human serum by qualitative and quantitative rapid latex slide test. RHELAX CRP slide test for detection of CRP is based on the principle of agglutination. The test specimen (serum) is mixed with RHELAX CRP latex reagent and allowed to react. If CRP concentration is greater than $0.6 \mathrm{mg} / \mathrm{dl}$ a visible agglutination is observed. If CRP concentration is less than $0.6 \mathrm{mg} / \mathrm{dl}$, then no agglutination is observed. No special preparation of the patient was required prior to specimen collection. $2 \mathrm{ml}$ venous blood was collected into sterile disposable tube and processed with centrifuge at $10,000 \mathrm{rpm}$ for serum separation. Only serum was used for testing. If there was delay in testing occurs then samples were stored at 2 to $8^{\circ} \mathrm{C}$.

\section{Dental Air Force Home Dental Cleaning System}

\section{Mechanism}

Dental Air Force is a home dental device. It is an electrical delivery device that uses a 1/8th HP oil-less electric air compressor air source with twin pistons connected to a handpiece by a pneumatic cord directed through a handpiece and tip where air at $40 \mathrm{psi}$ though a .020 size orifice has the introduction of a slurry of dental cleaner. This produces a jet stream of wet abrasive whereby the user directs the cleaner components and air into the sites between the teeth and below the gum line. Dental Air Force home dental cleaning system is a less powerful device that emulates a device used in the professional setting to polish teeth. Dental Air Force

Table 1: Distribution of patients in study groups

\begin{tabular}{lll} 
Groups & Patient clinical protocol & No. of patients \\
\hline Group A: & No modification of oral hygiene regime (oral hygiene by toothbrushing only) \\
Group B: & Oral hygiene by use of Dental Air Force home dental cleaning system \\
Group C: & Complete oral prophylaxis (scaling and root planing) followed by use of toothbrush only \\
Group D: & $\begin{array}{l}\text { Complete oral prophylaxis (scaling and root planing) followed by use of Dental Air Force home } \\
\text { dental cleaning system }\end{array}$
\end{tabular}


through electron microscopy has been shown to be much less abrasive than a toothbrush and toothpaste combination. There is no electricity in the handpiece and the air source can be turned on and off remotely through a pneumatic button on the handpiece. The manufacturer recommends twice a day usage for 2 to 3 minutes per use unless directed differently by their dentist or hygienist.

\section{Device}

Dental Air Force home dental cleaning system used in this study is approved by FDA Vide No. K001493 as medical device for plaque removal in order to prevent gingivitis. The appliance uses a precision jet of air to deliver water and dental cleaner to 'power wash' the mouth. Dental Air Force uniquely dispenses the dental cleaner by you controlling the amount of cleaner that is dispensed in your mouth. One normal application uses one teaspoon of dental cleaner. The cleaner ingredients include sodium bicarbonate, the most widely accepted and totally natural buffering agent that promotes a neutral environment. It also contains mint flavoring, Xylitol and Stevia as natural sweeteners. The formula is free of sodium lauryl sulfate, the ingredient in most toothpaste that causes sensitivity and irritation. Dental Air Force uses air and a dental cleaner with water to break through the plaque barrier. The air oxygenates the spaces between teeth and along the gum line, making it difficult for the anaerobic plaque-causing bacteria to live. Sodium bicarbonate is a neutralizing agent that acts on the acids produced by the bacteria. It is an abrasive that breaks up the plaque's sticky film. It also removes the odor caused by the plaque. The water flushes away the bacteria and debris off the surfaces of the teeth.

\section{RESULTS}

By applying students paired t-test between mean values of all parameters from baseline to 7 days, baseline to 15 days and 7 to 15 days in all the four groups following observation was seen as illustrated in Table 2. Highly significant results were seen in group $\mathrm{D}$ (i.e. $\mathrm{p}<0.01$ ), followed by significant results in group $\mathrm{C}$ (i.e. $\mathrm{p}<0.05$ ) and group $\mathrm{B}$ (i.e. $\mathrm{p}>0.05$ ). There is no change in parameters at group A (i.e. $\mathrm{p}>0.05$ ). Comparison of mean values of gingival scores, plaque score, clinical attachment level, probing depth and C-reactive protein level at 7th day and 15th day between groups $\mathrm{A}$ and $\mathrm{C}$, groups $\mathrm{B}$ and $\mathrm{C}$, groups $\mathrm{B}$ and $\mathrm{D}$ and finally groups $\mathrm{C}$ and $\mathrm{D}$ control group were highly significant $(\mathrm{p}<0.01)$. More significant and clinical result was seen in group $\mathrm{D}$ in all the parameters as compare to the groups A, B and C as shown in Table 3.

\section{DISCUSSION}

The patients using Dental Air Force home cleaning appliance show considerable decline in C-reactive protein (CRP) levels and further maintain the lower C-reactive protein (CRP) levels after phase I therapy as compared to groups $\mathrm{C}$ and $\mathrm{D}$. This improvement can be attributed to the fact that the $\mathrm{C}$-reactive proteins are produced in inflammatory conditions and once the inflammation subsided due to treatment the C-reactive protein level returned to normal. Further the level of CRP was maintained at lower level by scrupulous plaque control especially at the interdentally surfaces. Dental Air Force home cleaning system showed a significant result in achieving the same. This study found a similar correlation with the previous studies where they found as positive correlation between CRP and periodontitis patients. ${ }^{6-8}$ In this study, we observed a significant improvement in gingival score and plaque score following scaling and root planing (SRP), as documented in previous study ${ }^{9}$ and also this study correlates with the previous study conducted and found a significant decrease in serum CRP, but only after a period of 6 months. ${ }^{10}$ Observational nonexperimental studies have found similar

\begin{tabular}{llllll}
\multicolumn{5}{c}{ Table 2: Distribution of mean and standard deviation values (Mean $\pm \mathrm{SD}$ ) of all parameters at baseline (0 day), 7th and } \\
15th day in all the experimental groups $(\mathrm{A}, \mathrm{B}, \mathrm{C}$ and $\mathrm{D})$
\end{tabular}

GI: Gingival index; PI: Plaque index; CAL: Clinical attachment level; PD: Probing depth; CRP: C-reactive protein test and t-test: Student paired t-test 
Table 3: Distribution of mean values of all parameters at 7 th day and 15 th day in all the experimental groups $(A, B, C$ and $D)$ under the study

\begin{tabular}{|c|c|c|c|c|}
\hline Parameters & $\begin{array}{l}\text { Group A } \\
\text { Mean } \pm S D\end{array}$ & $\begin{array}{l}\text { Group B } \\
\text { Mean } \pm \text { SD }\end{array}$ & $\begin{array}{l}\text { Group C } \\
\text { Mean } \pm S D\end{array}$ & $\begin{array}{l}\text { Group D } \\
\text { Mean } \pm \text { SD }\end{array}$ \\
\hline \multicolumn{5}{|l|}{ GI } \\
\hline At 7 days & $2.60 \pm 0.29$ & $2.61 \pm 0.28$ & $1.90 \pm 0.29$ & $1.80 \pm 0.25$ \\
\hline At 15 days & $2.62 \pm 0.29$ & $2.62 \pm 0.29$ & $1.46 \pm 0.13$ & $1.42 \pm 0.14$ \\
\hline \multicolumn{5}{|l|}{ PI } \\
\hline At 7 days & $2.60 \pm 0.29$ & $2.61 \pm 0.28$ & $1.90 \pm 0.29$ & $1.80 \pm 0.25$ \\
\hline At 15 days & $2.62 \pm 0.29$ & $2.62 \pm 0.29$ & $1.46 \pm 0.13$ & $1.42 \pm 0.14$ \\
\hline \multicolumn{5}{|l|}{$C A L$} \\
\hline At 7 days & $2.60 \pm 0.29$ & $2.61 \pm 0.28$ & $1.90 \pm 0.29$ & $1.80 \pm 0.25$ \\
\hline At 15 days & $2.62 \pm 0.29$ & $2.62 \pm 0.29$ & $1.46 \pm 0.13$ & $1.42 \pm 0.14$ \\
\hline \multicolumn{5}{|l|}{$P D$} \\
\hline At 7 days & $2.60 \pm 0.29$ & $2.61 \pm 0.28$ & $1.90 \pm 0.29$ & $1.80 \pm 0.25$ \\
\hline At 15 days & $2.62 \pm 0.29$ & $2.62 \pm 0.29$ & $1.46 \pm 0.13$ & $1.42 \pm 0.14$ \\
\hline \multicolumn{5}{|l|}{ CRP } \\
\hline At 7 days & $2.60 \pm 0.29$ & $2.61 \pm 0.28$ & $1.90 \pm 0.29$ & $1.80 \pm 0.25$ \\
\hline At 15 days & $2.62 \pm 0.29$ & $2.62 \pm 0.29$ & $1.46 \pm 0.13$ & $1.42 \pm 0.14$ \\
\hline
\end{tabular}

GI: Gingival index; PI: Plaque index; CAL: Clinical attachment level; PD: Probing depth; CRP: C-reactive protein

results as this study that subjects who have periodontal infections, such as gingivitis and periodontitis have higher levels of CRP than subjects without gingivitis and periodontitis ${ }^{11-13}$ respectively, supporting the hypothesis that these oral infections increase CRP levels, moreover, some intervention studies have also support this study results that periodontal treatment reduces CRP levels. ${ }^{10,14}$ The results of the study showed that there was a 35\% decrease in CRP level in periodontitis patients that used Dental Air Force home dental cleaning system without undergoing phase 1 (complete scaling and root planing) therapy. This result will further open the gateway for the multiple longitudinal studies that will focus to further evaluate the maximum lower level of CRP which can be achieved by using Dental Air Force home dental cleaning system in periodontitis patients without undergoing phase 1 (complete scaling and root planing) therapy. There was $100 \%$ decrease in CRP in group D (phase 1 therapy followed by use of Dental Air Force home dental cleaning system) as compare to group C (phase 1 therapy followed by use of toothbrush) where there were $89.61 \%$ decrease in CRP level from baseline to 15th day of recordings. Thus, the efficacy of Dental Air Force home dental cleaning system is more efficient in preliminary phase of CRP control as compared to toothbrush. More and long clinical studies are needed to further examine the time period to which Dental Air Force home dental cleaning system will able to keep the CRP values at lower levels. Periodontitis has been proposed as having an etiological or modulating role in cardiovascular disease, diabetes, respiratory disease and adverse pregnancy outcome and several mechanisms have been proposed to explain or support such theories and oral lesions are indicators of disease progression and oral cavity can be a window to overall health and body systems. ${ }^{15}$ Locally produced inflammatory mediators, such as CRP, IL-1 $1 \beta$, interleukins 6 (IL-6), TNF- $\alpha$ are the key modulating agents in cardiovascular disease. Periodontitis creates a burden low level of systemic inflammatory reactants (CRP) bacterial pathogens, antigens, endotoxins and inflammatory cytokines (IL-1, IL-6, TNF- $\alpha$ ) that contribute to the process of atherogenesis and thromboembolic events. ${ }^{16}$ The results of this study showed that Dental Air Force home dental cleaning system significantly lowers the CRP level from baseline to 15th day in both groups B and D that uses Dental Air Force home dental cleaning system. Thus, by routine usage of this novel oral home hygiene devices will reduce the probability of systemic diseases associated with increased CRP levels, such as cardiovascular diseases. Applicability of this device is also in patients who have decreased manual dexterity, visibility (geriatric population) or those with special needs regardless of age.

\section{CONCLUSION}

Conclusively it could be stated from this study that there seems to be strong correlation between periodontal diseases and CRP level and as there is progression and remission of periodontal disease; CRP values follow the same. This study also concluded that there is positive effect of non-surgical periodontal therapy, i.e. scaling and root planning on lowering the serum CRP level. This suppression of CRP values will be maintained by meticulous plaque control and with newer innovative technology; such as Dental Air Force home cleaning system, this goal was well achieved and 
sustained as compared to use of traditional toothbrush only after phase I therapy. Dental Air Force home dental cleaning system with the access to interdentally area helps in preventing the accumulation of dental plaque biofilm, thus able to maintain the CRP at lower levels as compare to traditional toothbrushing after phase I therapy. Also with use of Dental Air Force home dental cleaning system there is minimal chances of cross-infection. Clinical studies had shown that Dental Air Force home dental cleaning system is more competent and effective in oral biofilm removal as compared to toothbrush. ${ }^{17}$ The study results clearly showed the potentials of Dental Air Force home dental cleaning system in both treatment and prevention of the chronic periodontitis in respect to reduction of CRP levels as seen in both group B and group D. This study also showed that by the regular use of Dental Air Force home dental cleaning system; there will be improvement in the systemic health of the individual users and the diseases that are associated with periodontal diseases (cardiovascular, diabetes, preterm low birth, pulmonary disease, etc.) will be controlled or prevented for longer duration of time.

\section{REFERENCES}

1. Saini R, Marawar PP, Shete S, Saini S. Periodontitis a true infection. J Global Infect Dis 2009;1:149-51.

2. Saini R, Marawar PP, Shete S, Saini S, Mani A. Dental expression and role in palliative treatment. Indian J Palliat Care 2009;15:26-29.

3. Saini R. Periodontitis and rheumatoid arthritis: Inflammatory relationship. J Pharm Bioallied Sci 2011;3:464.

4. Saini R, Saini S, Sharma S. Periodontitis lead to VAP in ICU patients: A dental note. J Pharm Bioallied Sci 2010;2:377.

5. Lowe GD. The relationship between infection, inflammation, and cardiovascular disease: An overview. Ann Periodontol 2000;6:1-8.

6. Slade GD, Offenbachor S, Beck JD, Heiss G, Pankow JS. Acute phase inflammatory response to periodontal disease in the US population. J Dent Res 2000;79:49-57.

7. Ide M, McPartlin D, Coward PY, Crook M, Lumb P, Wilson RF. Effect of treatment of chronic periodontitis on levels of serum markers of acute-phase inflammatory and vascular responses. J Clin Periodontol 2003;30:334-40.

8. Ebersole JL, Machen RL, Steffen, Willmann DE. Systemic acute- phase reactants, C-reactive protein and haptoglobin, in adult periodontitis. Clin Exp Immunol 1997;107:347-52.

9. Eugini MA, Haffajee AD, Smith C, Kent Jr, Socransky SS. The effect of sealing and root planing on the clinical and microbiological parameters of periodontal disease: 12 month results. J Clin Periodontol 2000;27:30-36.

10. Aiuto FD, et al. Periodontitis and atherogenesis: Causal association or simple coincidence. J Clin Periodontol 2004; 3:402-11.

11. Wu T, Trevisan M, Genco RJ, Falkner KL, Dorn JP, Sempos CT. Examination of the relation between periodontal health status and cardiovascular risk factors: Serum total and high density lipoprotein cholesterol, C-reactive protein, and plasma fibrinogen. Am J Epidemiol 2000;151:273-82.

12. Fritz $\mathrm{H}$, et al. Production of C-reactive protein and risk of coronary events in stable and unstable angina. Lancet 1997; 349:462-66.

13. Montebugnoli L, Servidio D, Miaton RA, Prati C, Tricoci P, Melloni C. Poor oral health is associated with coronary heart disease and elevated systemic inflammatory and haemostatic factors. J Clin Periodontol 2004;31:25-29.

14. Paraskevas S, Huizinga JD, Loos BG. A systematic review and meta-analyses on C-reactive protein in relation to periodontitis. J Clin Periodontol 2008;35:277-90.

15. Saini R, Saini S, Saini SR. Periodontal disease: A risk factor to cardiovascular disease. Ann Card Anaesth 2010;13:159-61.

16. Saini R, Saini S, Sharma S. Periodontal disease linked to cardiovascular disease. J Cardiovasc Dis Res 2010;1:161-62.

17. Piero P, Rajiv S. In: Saini S, Saini R (Eds). Hospital infection control: Clinical guidelines (1st ed). Hyderabad: Paras Medical Publisher 2012, p. 188-96.

\section{ABOUT THE AUTHORS}

\section{Ameet Mani}

Associate Professor, Department of Periodontology, Rural Dental College, Ahmednagar, Maharashtra, India

\section{Vinay Vadvadgi (Corresponding Author)}

Assistant Professor, Department of Periodontology, Rural Dental College Ahmednagar, Maharashtra, India, e-mail: periodontist29@gmail.com

\section{Raju Anarthe}

Assistant Professor, Department of Periodontology, Rural Dental College, Ahmednagar, Maharashtra, India

\section{Rajiv Saini}

Assistant Professor, Department of Periodontology, Rural Dental College, Ahmednagar, Maharashtra, India

\section{Shubhangi Mani}

Associate Professor, Department of Orthodontics, Rural Dental College, Ahmednagar, Maharashtra, India 